\title{
PENGARUH LATIHAN AKSELERASI BALANCE COORDINATION RUNNING TERHADAP PENINGKATAN HASIL BELAJAR LARI CEPAT PADA SISWA SEKOLAH DASAR
}

\author{
Ali Priyono \\ Universitas Majalengka, Indonesia \\ alipriyono@unma.ac.id
}

\begin{abstract}
ABSTRAK. Tujuan penelitian ini, adalah untuk mengetahui pengaruh latihan akselerasi balance coordination running terhadap peningkatan hasil belajar lari cepat pada siswa Sekolah Dasar. Metode yang di gunakan dalm penelitian ini adalah metode eksperimen, hal ini dimaksudkan karena masalah yang dihadapi mengungkapkan pengaruh sebab akibat. Tes pengumpulan data yang digunakan adalah tes. Alat ukur yang digunakan dalam penelitian ini adalah tes lari cepat 40 meter Populasi yang digunakan dalam penelitian ini adalah siswa putra 20 siswa. Sempel yang di ambil adalah seluruh populasi yaitu 20 siswa. Data yang diperoleh dari hasil pengumpulan tersebut, selanjutnya diolah dan di analisis dengan menggunakan statistik yang cocok. Yang pada akhirnya penelitian kelompok eksperimen dapat mengambil kesimpulan sebagai berikut : rata-rata tes awal 7.895 dan rata-rata tes akhir 6.820. Hasil perhitungan uji normalitas lilierfor tes awal 0.923 dan priode tes akhir 0.892: uji satu pihak (pihak kanan) $t$ hitung pada taraf a 0.05 berada di luar batas interval $\mathrm{t}$ table $(\mathrm{t}$ hitung $>\mathrm{t}$ table $=6.674>2.093$ atau $\mathrm{t}$ hitung $<\mathrm{t}$ table $=6.674<$ 2.093 ), maka dari itu data tersebut di ketahui ada perbedaan kelompok eksperimen pada tes awal dan akhir. Ini artinya kelompok eksperimen menunjukan adanya perkembangan yang berarti atau ada peningkatan dalam hasil latihan akselerasi balance coordination running terhadap peningkatan hasil belajar lari cepat pada siswa sekolah dasar. Dalam kata lain bahwa latihan akselerasi balance coordination running terhadap peningkatan hasil belajar lari cepat yang di lakukan secara teratur dalam jangka waktu empat minggu memberikan pengaruh yang berarti terhadap peningkatan hasil belajar lari cepat.
\end{abstract}

Kata Kunci: Akselerasi, Balance, Coordination, Running, Lari Cepat

\section{Pendahuluan}

Nomor lari merupakan nomor yang disebut sebagai nonteknik, karena lari merupakan aktivitas alami yang relatif sederhana jika dibandingkan dengan nomor lompat tinggi galah atau nomor lontar martil. Tidaklah sederhana itu pada nomor lari. Penekanan pada kecepatan dan dayatahan ditentukan oleh jarak lomba, start jongkok dalam lomba lari sprint (lari cepat) pergantian tongkat pada lari estafet dan adanya rintangan dalam nomor lari gawang dan halang rintang yang semuanya membuat tuntutan teknik untuk para atlet harus dipersiapkan.

Kebutuhan yang relatif penting untuk lari sprint (lari cepat) sangat beragam bergantung pada katagori usia (Ballesteros, 1999) tapi yang dibutuhkan untuk semua nomor dalam lari sprint (lari cepat) dan gawang adalah kecepatan (speed), sesuai dengan pengertian bahwa “sprint” yang berarti lari secepat-cepatnya. Kecepatan dalam lari sprint dan gawang adalah hasil kecepatan gerak dari kontraksi otot secara cepat dan kuat (powerful) melalui gerakan yang halus (smooth) dan efisien (efficient). kecepatan pada kontraksi otot bergantung pada komposisi otot. 
Proporsi dari serabut otot cepat (fast twitch fiber/FT) sangat erat kaitanya dengan gerakan kecepatan maxsimum (maximum speed of movement). Pelari sprint yang baik secara normal memiliki presentase yang lebih tinggi pada serabut otot cepat (FT). dari pada pelari jarak jauh, yang lebih banyak proporsinya pada serabut otot lambat (slow twitch fiber /ST). Karekteristik Tersebut merupakan faktor yang sudah dilahirkan oleh karena itu, untuk menjadi sprinter yang baik dan potensial, atlet harus didasari atas bakat yang didukung dengan teknik lari yang baik agar gerak lari menjadi efisien. Teknik lain dapat dipelajari,dilatih dan dikembangkan. Latihan juga dapat lebih dikembangkan melalui kemampan biomotor seperti kelenturan, kekuatan, yang kemudian dikembangkan menjadi kekuatan-kecepatan (power), koordinasi (coordination) dan daya tahan (endurance) .Berlarri cepat ( sprinting ) yang bisa anda lakukan dalam jarak pendek, mungkin nampak nya tidak sulit, tetapi ini tidaklah semudah kelihatanya. Dalam pengertinan sederhan, seorang pelari cepat harus memperoleh kecepatan tinggi dalam waktu sesingkat mungkin agar berhasil dalam perlombaan. Untuk ini ia harus memiliki start yang baik, mampu menambah kecepatan, dan mempertahankan kecepatan, maksimum untuk jarak yang tersisa. Ada tiga hal untuk meningkatka prestasi: teknis, fisiologis. Anda harus menghilangkan segenp gerak yang tidak perlu, untuk memperoleh tubuh yang bergerak cepat dalam tempo singkat, untuk penyempurnaan termasuk start, panjang langkah, irama langkah, serta pola gerak tubuh, latihan yang tepat, akan meningkatkan daya tahan (stamina) anda, kekuatan otot dan kelenturan, seorang pelari cepat juga harus memiliki pendekatan psikologis yang benar. Seorang pelari harus mengetahui kekuatan dan kelemahan lawan.

Lari cepat biasanya dimenangkan kurang dari satu meter atau sepersepuluh detik, maka dari itu penting sekali memiliki start yang baik. Banyak kekalahn dalam pertandingan terjadi di garis start, lebih pendek jarak perlombaan lebih penting lagi arti start itu. Maka perlu adanya latihan yang terus menerus, seperti yang dikemukakan oleh Coever (2007), bahwa "latihan teknik adalah soal mengulang dan sekali mengulang, sampai berhasil menguasai satu teknik secara sempurna”.

Latihan yang terus menerus akan terjadi peningkatan kemampuan siswa dalam berlari cepat karena dengan mengulang dan mengulang terjadi perubahan dan kemampuan bidang fisik dan psikis dibidang lari cepat, seperti yang dikemukakan oleh Imanudin (2008). bahwa latihan kondisi fisik lari cepat adalah sebagai beriktut:

1. Fisik umum terdiri dari: kekuatan (strength) daya tahan (endurance), kecepatan (speed), kelenturan (fleksibility) kelincahan (agility).

2. Fisik khusus terdiri dari : daya ledak (power), reaksi, stamina, koordinasi, keseimbangan, kecepatan. 
Untuk memperoleh peningkatan lari cepat dapat dilakukan melalui latihan akselerasi balance coordinasi running (abc running) bentuk latihan ini bertujuan untuk mengembangkan keterampilan dasar lari dan mengembangkan koordinasi gerak lari jarak pendek. Bentuk latihan tersebut dapat digunakan untuk meningkatkan kecepatan dalam lari cepat.

Latihan yang dibutuhkan untuk mencapai lari cepat adalah latihan akselerasi balance coordinasi running (abc running) dengan latihan yang giat akan menghasilkan kemampuan siswa dalam lari cepat, sebaliknya apabila latihan malas tidak teratur akan menghasilkan lari cepat yang kurang dalam berlari. Dengan demikian jelaslah bahwa latihan akselerasi balance coordinasi running (abc running) pada siswa sangat menentukan berhasil dan tidaknya dalam mencapai lari cepat, disinilah pentingnya melakukan latihan akselerasi balance coordination running (abc running) yang terus menerus.

Dengan latihan akselerasi balance coordination running (abc running) bagi siswa Sekolah Dasar idealnya dapat mencapai prestasi lari cepat yang tergolong baik, kenyataannya tidak sedikit siswa yang belum mampu mencapai lari cepat yang di targetkan 6 sampai 7 detik dengan jarak 40 meter. Dengan demikian jelaslah bahwa satu pihak latihan akselerasi balance coordination running (abc running) yang tergolong baik untuk mencapai kemampuan lari cepat, namun dipihak lain kenyataan masih banyak kemampuan siswa dalam berlari cepat masih di bawah standar yaitu antara 6 sampai 7 detik dengan jarak 40 meter.

Untuk menyelesaikan masalah tersebut maka penulis mencoba mencari solusi agar lari cepat tergolong baik dengan latihan acceleration balance coordination running (abc running) adalah latihan untuk meningkatkan kemampuan siswa dalam berlari cepat yang distandarkan yaitu antara 6 sampai 7 detik dengan jarak 40 meter.

\section{Acceleration Balance Coordination Running (Abc running)}

Teknik latihan abc running di bagi melingkupi latihan gerakan tungkai, gerakan lutut dan gerakan tangan sebagai berikut :

a. Gerakan tungkai

Diawali dengan sikap badan berdiri tegap kedua lengan bebas kesamping badan kemudian lakukan gerakan di tempat dengan mengangkat tumitkemudian letakan kembali ditanah, ujung kaki tetap nempel ke tanah bersamaan dengan itu kedua lengan ditekuk membentuk sudut 90 derajat dan digerakan mengikuti gerakan irama tungkai.

b. Teknik gerakan lutut abc running

Diawali dengan sikap berdiri tegak, kemudian lari ditempat dengan kedua kaki diluruskan kedepan secara bergantian kaki diangkat berlahan-lahan kemudian mengikuti irama 
semakin cepat, gerakan ini bisa dilakukan kira-kira 10-15 meter. Gerakan juga bisa diganti dengan tendangan kaki secara bergantian kepantatatau kearah belakang badan gerakan ini bisa dilakukan dengan cara melangkah maju kira-kira 10-15 meter.

c. Gerakan tungkai dan tangan

Diawali dengan sikap berdiri tegak, kedua lengan ditekuk membentuk sudut 90 derajat. Kemudian lari ditempat dengan gerakan mengangkat lutut tinggi, setinggi pinggul disertai geakan ayunan lengan. Ketika tungkai kanan diangkat dengan lutut setinggi pinggul lengan kiri diayun kedepan dengan kuat setinggi bahu dan kecepatan di tangan depan dada. Lakukan gerakan kedepan dengan gerekan yang cepat dengan jarak 10-15 meter.

\section{Konsep dari Acceleration Balance Coordination Running}

Serangkaian gerak lari dalam waktu yang bersamaan dan hampir bersamaan dengan harmonis yang di dalamnya tediri dari unsur geakan lari acceleration balance coordination running, yang kian hari, kian meningkat kecepatannya. Pembelajaran ini digunakan untuk memperbaiki kordinasi dan teknik lari sprint, berlatih bagian demi bagian secara benar dan secara perlahan dalam massa latihan secara formal.

\section{Pembelajaran Teknik Lari Sprint Dengan Latihan Gerak Lari ABC}

"Menurut Hendrayana (2007) Istilah gerak lari abc sebenarnya lebih diutamakan pada gerak yang bervariasi dan disusun berdasarkan sistematika berbagai bentuk gerakan kaki dari yang mudah ke yang sukar. Pembelajaran ini digunakan untuk memperbaiki koordinasi dan teknik lari sprint. Metode yang dapat diterima untuk mengembangkan teknik sprint adalah berlatih bagian secara benar dan secara perlahan dalam masa latihan secara formal. Segera tingkatkan kecepatan berlari sesudah melakukan gerakan dengan irama yang benar. Jarak yang dianjurkan adalah 10-15 meter dengan 2 sampai 3 kali pengulangan. Kamu boleh berjalan ketika kembali ketempat semula".

a. Berjalan dengan Lutut Diangkat Tinggi

Cobalah jalan perlahan, angkatlah paha depan dengan kuat sampai pada posisi sejajar dengan tanah. Kedua tangan ditekuk dengan sudut siku sebesar 90 derajat. Tungkai pendukung diluruskan penuh dari ujung kaki bersamaan ketika kamu mengangakat lutut yang berlawanan. Untuk memudahkan melakukan gerakan.

b. Berjalan dengan Lutut Diangkat Tinggi Disertai dengan Pelurusa Bagian Bawah Tungkai

Berbeda dengan latihan yang terdahulu disini tungkai diluruskan setelah paha diangkat tinggi sejajar dengan tanah. Latihan dilakukan seperti yang sudah dilakukan sebelumnya. Kamu 
meluruskan tungkai kiri sampai berdiri diatas ujung kaki, mengangkat paha kanan sampai sejajar dengan tanah, kemudian meluruskan bagian bawah tungkai sampai tungkai kanan dalam keadaan lurus dan sejajar dengan tanah. Tungkai kanan diturunkan dan diinjakan ditanah. Kemudian kaki kiri dilangkah kan ke depan dengan wajar untuk mengulangi gerakan selanjutnya. Sekarang tungkai kanan diliruskan dan berdiri dengan pergelangan kaki lurus, angkat tungkai kiri keatas sampai paha dalam posisi sejajar dengan tanah, kemudian luruskan bagian bawah tungkai ini sampai dalam keadaan lurus. Kemudian injakan kaki kiri ditanah, dan kaki kanan dilangkahkan dengan wajar, untuk melakukan gerakan berikutnya. Langkahlangkah ini dilakukan berulang- ulang. Paha tetap dalam keadaan tinggi ketika tungkai bagian bawah diluruskan.

c. Meloncat - Loncat dengan Lutut Diangkat Tinggi Disertai dengan Pelurusan Bagian Bawah Tungkai

Latihan ini cukup aktif. Lonctan cukup dilakukan 3 sd 4 langkah pendek dengan beberapa kali istirahat. Aktivitas loncatan sama dengan loncat tali. Seperti latihan yang terdahulu, lakukanlah seolah-olah kamu mau melompati tali. Kedua paha diangkat horizontal, dan bagian bawah tungkai ditendangkan sampai posisi tungakai dalam keadaan lurus. Pandangan lurus kedepan, kedua lengan membentuk sudut 90 derajat di bagian sikut dan ayunkan ke duanya kedepan dan kebelakang dengan kuat.

\section{d. Menendang Pantat (Hit Kick)}

Setiap kamu bergerak pelan kedepan, tendangkan tumit kebelakang dan cobalah untuk dapat menyentuh pantat. Latihan ini untuk membantu membentuk gerakan menendang kebelakang badan dan memperlonggar otot quadricep.

e. Gerakan Lengan Lari Sprint

Dalam latihan ini kamu berkonsentrasi pada pemeliharaan sudut lengan pada siku sebesar 90 derajat dan ayunan kedepan dan kebelakang harus paralel dengan arah lari. Gerakan ini dimulai dengan berdiri ditempat, kemudian sambil jalan, lari pelan dan sprint.

f. Berlari dengan Lutut Diangkat Tinggi Diikuti Acceleration Sprint.

Bergerak lah kedepan sejauh 5 meter, mengutamakan pengangkatan lutut tinggi tetapi tanpa meluruskan bagian bawah tungkai. Pada isyarat tertentu secara serentak sprint sejauh 10 meter berakselerasi secepat mungkin.

\section{Lari Cepat dengan Tahanan}

Tahap ini bertujuan untuk mengembangkan tahap dorong atau support phase dan kekuatan khusus. Pada tahap ini dapat menggunakan tahanan dari teman atau suatu alat penangan 
misalnya ban mobil atau beberapa ban motor, lakukan dngan tidak melebihi berat tahanan, serta guru memperhatikan kaki topang betul-betul lurus dan kontak dengan tanah sesingkat mungkin.

\section{Lari Mengejar}

Tahap ini bertujuan untuk mengembangkan kecepatan reaksi dan percepatan lari. Latihan ni dapat menggunakan tomgkat atau tali sepanjang 1,5 m; mulailah dengan berlari pelan-pelan setelah teman pasangan di depan melepaskan tongkat atau tali siswa yang dibelakang mengejar sampai batas yang telah ditentukan.

2. Lari Percepatan

Tahap ini bertujuan untuk mengembangkan lari percepatan dan keceatan maksimum. Buatlah tanda untuk menandai daerah $6 \mathrm{~m}$, satu teman menunggu di ujung batas yang telah ditentukan, dan pelari yang dibelakang berlari optimum dan percepatlah berlari bila pelari yang dating mencapai daerah $6 \mathrm{~m}$ dan pelari yang di depan mulai berlari secepat mungkin bila pelari belakang telah menginjak garis $6 \mathrm{~m}$ dibelakangnya.

\section{Metode Penelitian}

Dalam penelitian ini penulis menggunakan motode eksperimen. Metode eksperimen diterapkan untuk melihat adanya sebab akibat dari suatu perlakuan. Yang dimaksud perlakuan dan dalam penelitian ini adalah kelompok sample yang diberi latihan $A B C$ running.

Dalam eksperimen ini ada 2 variable yang menjadi perhatian peneliti yaitu :

1. Latihan akselerasi balance coordinasi (abc running)

2. Peningkatan hasil belajar lari cepat.

Rancangan Penelitian yang digunakan dalam penelitian yang penulis laksanakan ini adalah metode eksperimen. Adapun metode yang digunakan dalam penelitian ini adalah "pretest and post-test grup"Arikunto (2013):

Tabel 3.1

Desain Penelitian

$01 \quad \mathrm{X} \quad 02$

Ket :

$01 \quad$ : pre-test

$\mathrm{X} \quad$ : ekperimen (pengaruh latihan akselerasi balance coordination running)

02 : post-test

Adapun yang menjadi populasi dalam penelitian ini adalah siswa kelas V SD Negeri 1 Kedongdong Kecamatan Susukan Kabupaten Cirebon siswa putra dan putri. Sebanyak 61 siswa putra dan putri. 
Teknik pengambilan sampel yang digunakan dalam penelitian ini adalah semua populasi dijadikan sampel oleh karena itu penelitian disebut juga penelitian populasi. Seperti yang dijelaskan Arikunto (2002) sebagai berikut: ' untuk sekedar ancer-ancer apabila subyek kurang dari 100, lebih baik diambil semua sehingga penelitian merupakan penelitian populasi'. Kemudian Surakhman (2002), menjelaskan bahwa 'penarikan sampel ini ditiadakan sama sekali dengan memasukan seluruh populasi sebagai sampel, yakni selama jumlah populasi itu terbatas'.

Berdasarkan penjelasan tersebut, maka jumlah penelitian yang penulis tetapkan sebesar $21 \% \pm$ dari 61 siswa yaitu 20 siswa. Jumlah sampel tersebut juga untuk mempermudah perhitungan statistik. Pengambilan sampel yang penulis lakukan adalah terdiri dari:

a. Siswa Kelas V Sekolah Dasar Negeri 1 Kedongdong Kecamatan Susukan Kabupaten Cirebon,

b. Jenis kelamin laki-laki,

c. Tidak cacat fisik,

d. Kemampuan sedang.

Instrumen dalam penelitian ini yaitu dengan menggunakan Kompetensi Dasar yang sesuai dengan Kurikulum SD yang akan menjadi alat bantu dalam menilai proses selama mengikuti pembelajaran latihan akselerasi balance coordination running terhadap peningkatan hasil belajar lari cepat pada siswa SDN Negeri 1 Kedongdong Kecamatan Susukan Kabupaten Cirebon. Alat ukur yang digunakan dalam penelitian ini adalah tes lari cepat.

Adapun untuk mengetahui kemampuan siswa dalam berlari cepat dengan tes lari cepat 40 meter.

Tujuan : Untuk mengetahui kecepatan lari seseorang

Alat/fasilitas:

1. Lintasan lurus, rata dan tidak licin, jarak antara garis start dan finish 40 meter

2. Peluit.

3. Stop wacth.

Bendera start dan bendera tiang pancang

Pelaksanaan : Subyek berdiri dibelakang garis start dengan sikap berdiri, aba-aba "ya" subyek berlari kedepan secepat mungkin menempuh jarak 40 meter. Pada saat subyek menyentuh melewati garis finish stop watch dihentikan.

Kesempatan lari diulang bilamana:

1. Pelari mencuri start

2. Pelari terganggu oleh pelari lainnya 
Skor : Skor hasil tes yaitu waktu yang dicapai oleh pelari untuk menempuh jarak 40 meter. Waktu dicatat sepersepuluh detik.

Jarak tempuh berdasarkan kelompok umur dan jenis kelamin,

Keterangan : pencatatan waktu dalam satuan detik dengan satu dibelakang koma.

Teknik analisis data yang penulis gunakan yaitu:

1. Uji normalitas data

2. Uji Homogenitas Data

3. Uji Hipotesis

4. Pengujian Hipotesis Dengan Kriteria Sebagai Berikut :

- jika t hitung < t table, maka hipotesis Ho diterima

- jika t hitung > t tabel, maka hipotesis Ho ditolak

\section{Hasil dan Pembahasan}

Setelah diadakan perhitungan dari data pelaksanaan tes lari cepat 40 meter penilaian didapatkan t-hitung 6.674 besar dari pada t-tabel 2.093 jadi hipotesis bisa diterima. Dengan kata lain dapat dikatakan bahwa terdapat pengaruh yang signifikan dari latihan akselerasi balance coordination running terhadap peningkatan hasil belajar lari cepat pada siswa kelas V SDN 1 Kedongdong Kecamatan Susukan Kabupaten Cirebon.

Istilah gerak lari abc sebenarnya lebih diutamakan pada gerak yang bervariasi dan disusun berdasarkan sistematika berbagai bentuk gerakan kaki dari yang mudah ke yang sukar. Pembelajaran ini digunakan untuk memperbaiki koordinasi dan teknik lari sprint. Metode yang dapat diterima untuk mengembangkan teknik sprint adalah berlatih bagian secara benar dan secara perlahan dalam masa latihan secara formal. Segera tingkatkan kecepatan berlari sesudah melakukan gerakan dengan irama yang benar. Jarak yang dianjurkan adalah 10-15 meter dengan 2 sampai 3 kali pengulangan. Kamu boleh berjalan ketika kembali ketempat semula.

\section{Kesimpulan}

Berdasarkan hasil perhitungan dan analisis data diperoleh kesimpulan sebagai berikut: Peningkatan hasil belajar lari cepat dipengaruhi oleh latihan akselerasi balance coordination running yaitu dengan nilai Sig. $(0.000)<0.05$, maka Ho diterima dan Hi ditolak. Dan didapatkan nilai t-hitung 6.674 > nilai t-tabel 2.093 sehingga hipotesis alterntif dalam penelitian ini diterima.

Jadi terdapat pengaruh yang signifikan dari hasil belajar lari cepat antara tes awal dan tes akhir. Sehingga hipotesis dalam penelitian ini diterima. Jadi terdapat pengaruh yang 
signifikan dari latihan akselerasi balance coordination running terhadap peningkatan hasil belajar lari cepat pada siswa kelas V SDN 1 Kedongdong Kecamatan Susukan Kabupaten Cirebon.

\section{Daftar Pustaka}

Abdurahman, M. (2003). Pendidikan bagi anak berkesulitan belajar. Jakarta: Rineka cipta Arikunto, S. (2013). Prosedur Penelitian Suatu Pendekatan Praktek. Jakarta: Rineka Cipta Arikunto, S. (2002). Prosedur Penelitian ( Suatu Pendekatan Praktek). Jakarta: Penerbit Rineka Cipta. Berliana dkk. (2008). Modul belajar pembelajaran dalam pelatihan olahraga, Pendidikan Kepelatihan Olahraga UPI. Bandung.

Cooper, W.(2007). Program latihan. CV. Akademika Pressindo: Jakarta

Didik, Z. S. (2010). Mengajar Dan Melatih Atletik, Bandung Penerbit PT: Remaja Fred Rosdakarya.

Dwi, P. (2010). Step By Step SPSS 17 Analisis Data Statistik. Yogyakarta: Andi Yogyakarta

Fred, M. (2008). Dasar - Dasar Atletik, Bandung, Percetakan Angkasa.

Harsono (2007) Manusia Dan Olahraga, Bandung : Giriwijoyo ITB Bandung

Hendrayana, Y. (2007) Bermain Atletik. Bandung: Fakultas Pendidikan Olahraga dan Kesehatan Unuversitas Pendidikan Indonesia.

Imanudin, I. (2008). Ilmu Kepelatihan Olahraga, Program Studi Keolahragaan Fakultas Pendidikan Olahraga Dan Kesehatan Universitas Pendidikan Indonesia

Nurhasan. (2007). Tes Dan Pengukuran Keolahraga, jurusan pendidikan kepelatihan fakultas pendidikan olahraga dan kesehatan universitas indonesia.

Lutan, R.,dkk. (2007). Evaluasi Pendidikan Jasmani, Bandung, Universitas pendidikan indonesia.

Sanjoto, m. (2007), Peningkatan dan pembinaan kekuatan kondisi fisik dalam olahraga. Dahara prize, Semarang

Sudjana. (2005). Dasar-dasar proses belajar mengajar. Bandung: sinar baru algalindo offset.

Sugiyono. (2013). Metode Penelitian Pendididkan, Bandung: Penerbit Alfabeta.

Sugiyono. (2010). Metode penelitian kuantitatif kualitatif dan R\&D, Bandung: ALFABETA

Sunaryadi. (2008) Modul Analisis Mekanika Olahraga. Bandung: Jurusan Pendidikan Kepelatihan Olahraga.

Surakhmad, W. (2000), Pengantar Ilmiah Dasar Metode Dan Teknik. Bandung: Tarsito. 